\title{
A BMJ for India
}

\section{This week the $B M J$ launches a dedicated online edition of the journal for doctors in India}

\author{
David Payne editor, bmj.com
}

BMJ, London WC1H 9JR, UK

BMJ India is the default setting for visitors to bmj.com from India, with a homepage that prioritises articles of interest and relevance to our readership of Indian doctors, researchers, policy makers, and other healthcare professionals.

The website's other main content channels_research, education, news, and comment—also prioritise articles of interest to Indian readers.

The site also displays feeds that show which articles have been most read and shared in India and links to the latest posts from the journal's growing community of bloggers (http://blogs.bmj. $\mathrm{com} / \mathrm{bmj} /$ category/india/) based in India.

BMJ India will be formally unveiled this week at a series of roadshows taking place in Delhi, Kolkata, Chennai, and Mumbai.

The events, being held to support plans by the Indian government for universal health coverage, involve representatives of the British High Commission and $B M J$ editors, including editor in chief Fiona Godlee and BMJ India editor Anita Jain (www.bmj.com/about-bmj/editorial-staff/anita-jain).

Dr Jain, who is based in Mumbai, said, "This tailor made offering includes all of the BMJ's internationally acclaimed content, along with a rich mix of high quality research and commentary on Indian medicine and healthcare, designed to help doctors practise the best possible medicine and ensure the best possible outcomes for their patients."

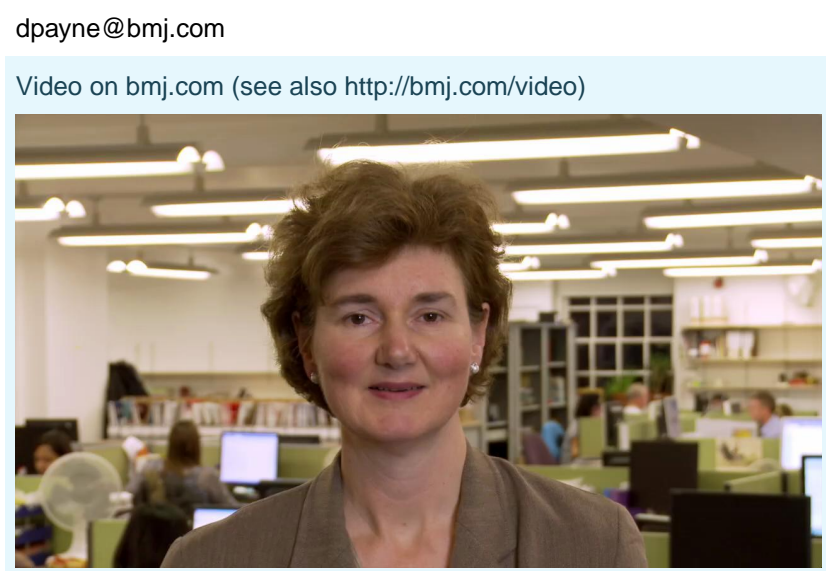

Dr Anita Jain, BMJ India editor, talks us through the website
Dr Jain and Dr Godlee have produced a short video guide to BMJ India.

The journal has developed its editorial presence in India by expanding its stable of freelance news and comment writers; this is underpinned by an outreach programme that also aims to increase the number of research and education papers submitted for publication.

Each year more than 14.5 million doctors, researchers, and other healthcare professionals visit bmj.com for the latest developments in global medicine. Of that figure, half a million come from India (our fifth highest traffic source), and the number is growing.

Because the journal's Indian readers are also interested in articles about medicine from other countries, BMJ India's main content channels (research, education, news, and comment) also display articles of interest to doctors worldwide. These channels will suppress articles solely about UK healthcare and the NHS.

The launch of BMJ India forms part of an ongoing editorial strategy to launch online editions of the journal, which began in September 2012 when a US edition went live. ${ }^{1}$ A UK edition followed shortly after. Readers can access any of these editions by clicking on the dropdown menu at the top of all pages on bmj.com.

Other national editions may be launched over time, but an immediate priority for 2013 is to improve the display of bmj.com on mobile devices. 
This is particularly pressing in India, where visits from mobile devices more than doubled between 2011 and 2012, from 11 108 to 24368 . India's mobile network is the second largest in the world. In 2012 more than half of all mobile phone sales were smart phones.

The launch of BMJ India is an important development in the journal's online offerings to readers based in the subcontinent. In 1995 the $B M J$ became the first general medical journal with a global internet presence. ${ }^{2}$ Three years later the arrival of article based "rapid responses" enabled Indian doctors to discuss medical developments with colleagues around the world. ${ }^{3}$

Since 2009 BMJ Learning has held nine Masterclass events in India, which were attended by more than 1900 Indian doctors working in both primary and secondary care. A further series of six video conferences attracted thousands of viewers across multiple sites.

As an international journal dating back to 1840 , the BMJ's interest in India pre-dates all of these developments. Perhaps the earliest example was a campaign by Ernest Hart, ${ }^{4} B M J$ editor from 1866 to 1898 , to persuade the Indian government to improve sanitation as a means of preventing cholera outbreaks. His 1898 obituary in the New York Times references his 15 pamphlets, among them The Sanitary Needs of India.

These days India faces different healthcare challenges. Rising incomes, a growing population of older people, changing demographics and disease profiles, and the increase in lifestyle diseases are all fuelling the demand for improved healthcare standards. Communicable diseases also remain a major problem, and in some cases are on the rise.

$B M J$ editor in chief Fiona Godlee said, "The $B M J$ aims to improve health and make a real difference to clinical practice worldwide.

"We are delighted to be supporting India's ambition to become a world leader in medical training and research, by providing an outlet for the work and opinions of India's doctors. We want to work with Indian states and institutions to provide the widest possible access to our content."

Tim Brooks, chief executive officer of the BMJ Group, added, "It is an honour to be a part of this historic transformation of India's health system. Our team here in India, and colleagues in the United Kingdom, look forward to a long and positive relationship with both the government and doctors across India."

Competing interests: I have read and understood the BMJ Group policy on declaration of interests and have no relevant interests to declare.

Provenance and peer review: Not commissioned; not externally peer reviewed.

1 Payne D, Godlee F. A BMJ for the United States. BMJ 2012;345:e6628. Delamothe T. BMJ on the internet. BMJ 1995;310:1343.

Crossan L, Delamothe T. Letters to the editor: the new order. BMJ 1998;316:1406.
The late Mr. Ernest Hart. BMJ 1898;1:785.1. www.bmj.com/content/1/1942/785.1.

Cite this as: BMJ 2013;346:f705

๑ B BMJ Publishing Group Ltd 2013 